\title{
Ein 5-Sterne-Editors' Choice und 4 TOP Produkte
}

Die TOP Produkt-Auszeichnungen des Dental Advisors werden jedes Jahr aufmerksam verfolgt. Als Neuzugang unter den Preisträgern präsentiert sich das zur IDS 2015 eingeführte Universalbonding iBOND Universal. Es erhielt prestigeträch-

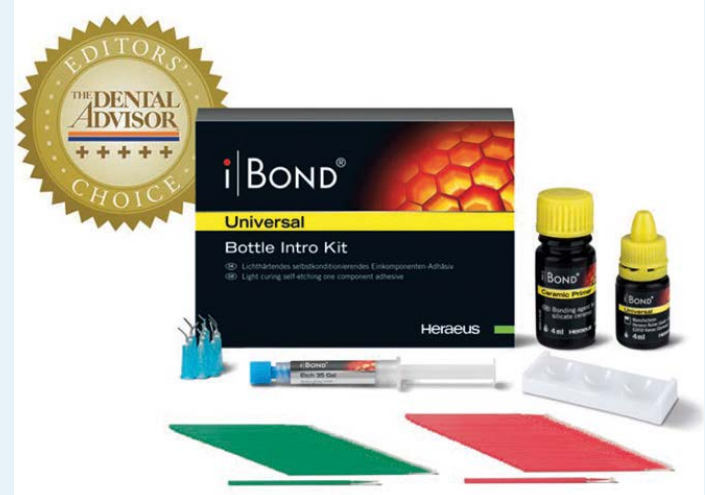

tige 5 Sterne und setzte sich direkt als Editors' Choice - Wahl der Redaktion - durch. iBOND Total Etch gewann bereits zum 5. Mal in Folge den Preis als TOP Bonding der 5. Generation. Wie schon im vergangenen Jahr wurde zudem Venus Pearl als TOP ästhetisches Komposit ausgezeichnet, xantasil als TOP Alginat-Alternative und Dynamix speed als TOP dynamisches Mischgerät. Die Auszeichnungen des Dental Advisors werden jedes Jahr sorgfältig aus Hunderten von Anwärtern ausgewählt. Entscheidend für die Auszeichnung ist ihre Leistungsfähigkeit in der Verwendung durch praktizierende Zahnärzte.

Nach einer Pressemitteilung der Heraeus Kulzer GmbH, Hanau www.heraeus-kulzer.de 